\title{
Aerosol effects on clouds and climate
}

\section{Journal Article}

Author(s):

Lohmann, Ulrike

Publication date:

2006

Permanent link:

https://doi.org/10.3929/ethz-b-000024256

Rights / license:

In Copyright - Non-Commercial Use Permitted

Originally published in:

Space Science Reviews 125(1-4), https://doi.org/10.1007/s11214-006-9051-8 


\title{
AEROSOL EFFECTS ON CLOUDS AND CLIMATE
}

\author{
U. LOHMANN \\ Institute for Atmospheric and Climate Science, ETH Zurich, Universitätsstr. 16, \\ CH-8092 Zurich, Switzerland \\ (E-mail: ulrike.lohmann@env.ethz.ch)
}

(Received 23 August 2005; Accepted in final form 3 November 2005)

\begin{abstract}
Aerosols affect the climate system by changing cloud characteristics in many ways. They act as cloud condensation and ice nuclei, they may inhibit freezing and they could have an influence on the hydrological cycle. While the cloud albedo enhancement (Twomey effect) of warm clouds received most attention so far and traditionally is the only indirect aerosol forcing considered in transient climate simulations, here I discuss the multitude of effects.
\end{abstract}

Keywords: aerosols, clouds, climate

\section{Introduction}

The burning of fossil fuels and biofuels due to human activities has greatly increased the amount of particular matter in the atmosphere. The major aerosol components are mineral dust, sea salt, sulfates, nitrates, black carbon (also termed soot) and particulate organic matter (POM). The natural aerosol species, mineral dust and sea salt, dominate the mass concentration in the atmosphere. On average they contribute $39 \mathrm{mg} \mathrm{m}^{-2}$ and $13 \mathrm{mg} \mathrm{m}^{-2}$ whereas the anthropogenic components, sulfate, POM and black carbon only contribute $3.9,3.3$ and $0.4 \mathrm{mg} \mathrm{m}^{-2}$ to the annual global average as deduced from 20 different global models (Kinne et al., 2006). So far, nitrate is not included in most models, because of its semi-volatile nature.

Optically, mineral dust and sea salt are less important because of their larger size. Thus, mineral dust and sea salt each contribute only as much to the aerosol optical depth as sulfate does (25\%). Black carbon, which contributes only $3 \%$ to the optical depth, is the main aerosol type that absorbs solar radiation and can lead to a warming of the surrounding air. This warming can prevent cloud formation because the atmosphere becomes more stable or even lead to an evaporation of cloud droplets (e.g., Koren et al., 2004). This so-called semi-direct effect thus counteracts some of the negative aerosol forcings from scattering aerosols, such as sea salt and sulfate, at the top-of-the atmosphere (TOA) (e.g., Lohmann and Feichter, 2005).

Aerosols also act as condensation centers for cloud droplets and ice crystals, thereby changing cloud properties. If more aerosol particles compete for the uptake of water vapor, the resulting cloud droplets do not grow as large. More smaller cloud droplets have a larger surface area than fewer larger cloud droplets for the 

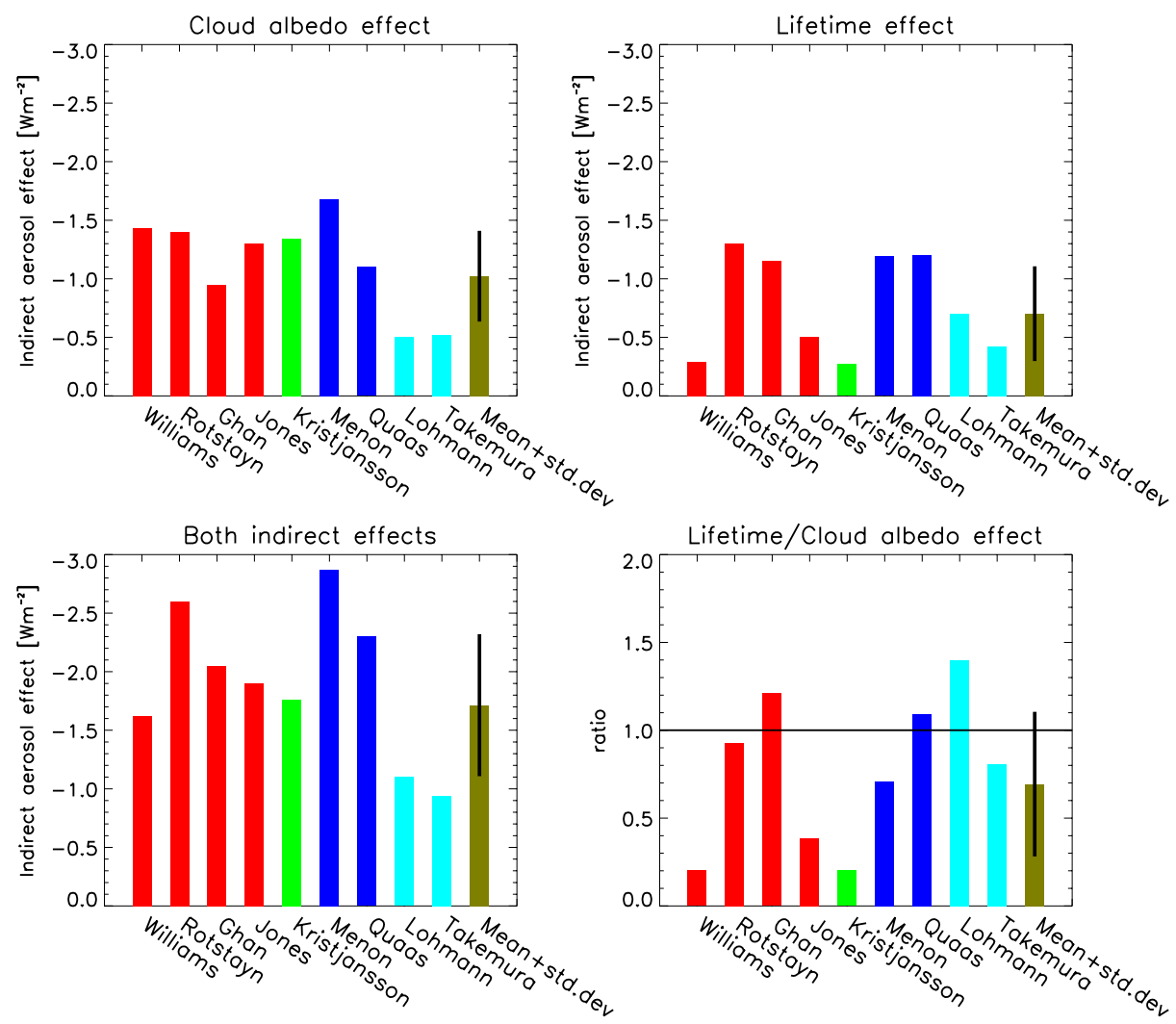

Figure 1. Global mean cloud albedo effect, lifetime effect, both effects combined and the ratio lifetime effect/cloud albed effect of anthropogenic sulfate aerosols (red bars) from Williams et al. (2001), Rotstayn and Penner (2001), Ghan et al. (2001) and Jones et al. (2001), of anthropogenic sulfate and black carbon (green bars) from Kristjánsson (2002), of anthropogenic sulfate and organic carbon (blue bars) from Menon et al. (2002) and Quaas et al. (2004), of anthropogenic sulfate and black and organic carbon (turquoise bars) from Lohmann et al. (2000) and Takemura et al. (2005), and the mean plus standard deviation from all simulations (olive bars). The results from Menon et al. (2002) and Ghan et al. (2001) are taken to be the averages of the simulations for only the cloud albedo effect and for both effects.

same amount of cloud water. Thus, a polluted cloud reflects more solar radiation back to space, resulting in a negative radiative forcing at TOA (cloud albedo effect). In addition, these more numerous but smaller cloud droplets collide less efficiently with each other, which reduces the precipitation efficiency of polluted clouds and presumably prolongs their lifetime (cloud lifetime effect). It also implies more scattering of solar radiation back to space, thus reinforcing the cloud albedo effect. Whether the cloud lifetime or the cloud albedo effect is more important, is still an open question. Whereas some models predict that the cloud albedo effect is four times as important as the cloud lifetime effect, other models predict that the cloud lifetime effect dominates over the cloud albedo effect (Figure 1). 
The global mean magnitude of the cloud albedo effect since pre-industrial times is estimated between -0.5 and $-1.9 \mathrm{Wm}^{-2}$ from different climate models and the cloud lifetime effect to be between -0.3 and $-1.4 \mathrm{Wm}^{-2}$ (Lohmann and Feichter, 2005). The semi-direct effect, which could in principle counteract part of this negative forcing at TOA, is predicted to be only between -0.5 and $+0.1 \mathrm{Wm}^{-2}$, where the negative values result from black carbon being located above the cloud. If the individual indirect effect values are summed up, the indirect effect could amount to almost $-3 \mathrm{Wm}^{-2}$. This exceeds estimates from simple inverse models, that start from the observed land temperature raise and increased ocean heat uptake in the 20th century, which bracket the overall indirect aerosol effect to be between 0 and $-2 \mathrm{Wm}^{-2}$ (Anderson et al., 2003). Thus, either climate model predictions of the cloud albedo and/or cloud lifetime effect are too large, or a counteracting effect is missing.

A proposed counteracting effect could include the ice phase (glaciation effect). Here increases in ice nuclei in the present-day climate result in more frequent freezing of supercooled clouds. As the precipitation formation in ice clouds is faster than in water clouds, this would increase the overall amount of precipitation. A climate model prediction including this effect resulted in reduced cloud cover at mid and high latitudes of the Northern Hemisphere and more of solar radiation absorbed within the Earth-atmosphere system, thus partly offsetting the indirect effects on warm clouds (Lohmann, 2002). Lohmann and Diehl (2006) extended this approach by introducing new parameterizations of contact freezing and immersion freezing in stratiform mixed-phase clouds for black carbon and mineral dust assumed to be composed of either kaolinite (simulation KAO) or montmorillonite (simulation MON) in the ECHAM4 general circulation model from a compilation of laboratory studies. The rather subtle differences between these sensitivity simulations in the present-day climate have significant implications for the anthropogenic indirect aerosol effect. The decrease in net radiation in these sensitivity simulations at the top-of-the-atmosphere varies from $1 \pm 0.3 \mathrm{Wm}^{-2}$ to $2.1 \pm 0.1 \mathrm{Wm}^{-2}$ depending on whether dust is assumed to be composed of kaolinite or montmorillonite. In simulation $\mathrm{KAO}$, black carbon has a higher relevancy as an ice nucleus than in simulation MON, because kaolinite is not freezing as effectively as montmorillonite. In simulation KAO, the addition of anthropogenic aerosols results in a larger ice water path, a slightly higher precipitation rate and a reduced total cloud cover. On the contrary, in simulation MON the increase in ice water path is much smaller and globally the decrease in precipitation is dominated by the reduction in warm-phase precipitation due to the indirect cloud lifetime effect (Figure 2).

Aerosols may also influence convective clouds (Rosenfeld and Woodley, 2000). Using a detailed cloud microphysics model Khain et al. (2005) found that smaller cloud droplets, such as originating from human activity, reduce the production of drizzle drops in convective clouds. When these droplets freeze, the associated latent heat release results in more vigorous convection. In a clean cloud, on the other hand, 
(a) Aerosol optical depth

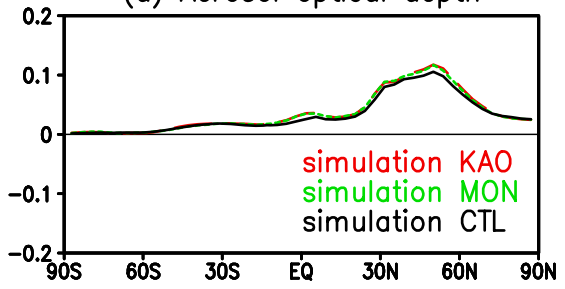

(c) Liquid water path $\left[\mathrm{g} \mathrm{m}^{-2}\right]$

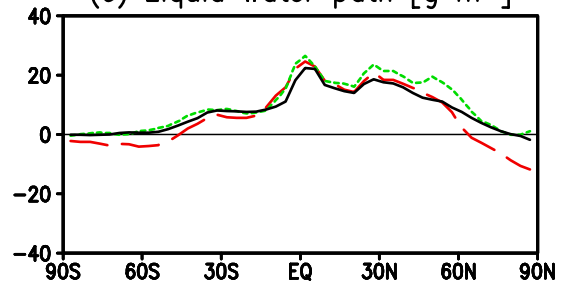

(e) Total precipitation $\left[\mathrm{mm} \mathrm{d}^{-1}\right]$

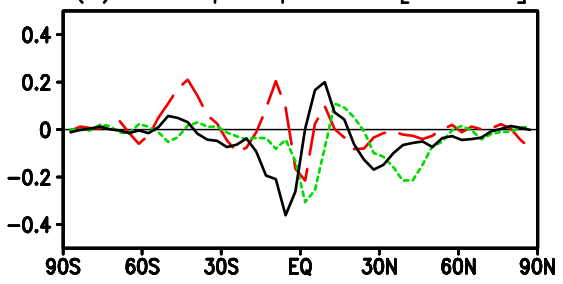

(g) SW radiation TOA $\left[\mathrm{W} \mathrm{\textrm {m } ^ { - 2 } ]}\right.$

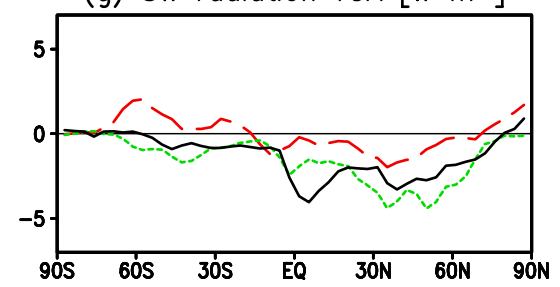

(b) Total cloud cover [\%]

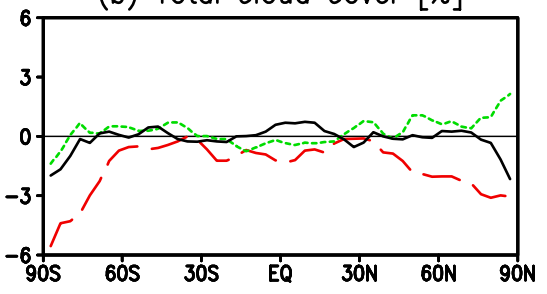

(d) Ice water path $\left[\mathrm{g} \mathrm{m}^{-2}\right]$

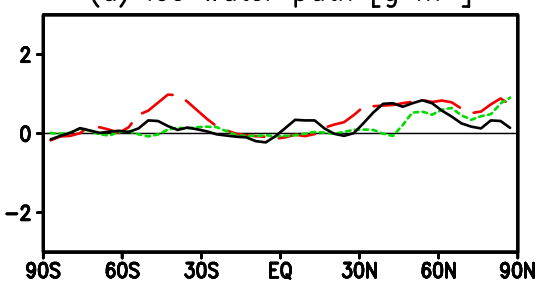

(f) Net radiation TOA $\left[\mathrm{W} \mathrm{m} \mathrm{m}^{-2}\right]$

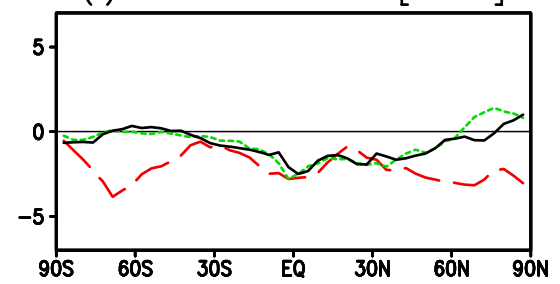

(h) LW radiation TOA $\left[\mathrm{W} \mathrm{m^{-2 } ]}\right.$

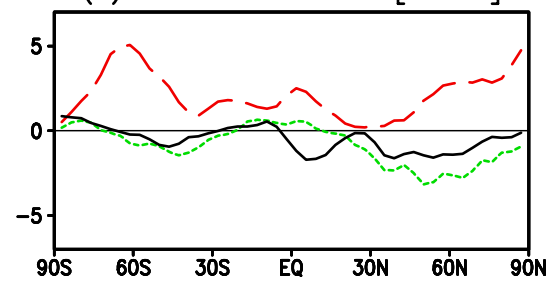

Figure 2. Zonal, annual mean changes in (a) aerosol optical depth, (b) total cloud cover, (c) liquid water path $\left(\mathrm{g} \mathrm{m}^{-2}\right)$, (d) ice water path $\left(\mathrm{g} \mathrm{m}^{-2}\right)$, (e) total precipitation $\left(\mathrm{mm} \mathrm{d}^{-1}\right)$, (f) TOA net, $(\mathrm{g})$ shortwave $(\mathrm{SW})$, and $(\mathrm{h})$ longwave $(\mathrm{LW})$ radiation between pre-industrial and present day times for the reference simulation CTL (solid line), simulation KAO (dashed line) and MON (dotted line). For more details, please refer to Lohmann and Diehl (2006).

drizzle would have left the cloud so that less latent heat is released when the cloud glaciates resulting in less vigorous convection. Therefore, no squall line is formed with maritime aerosol concentrations, but the squall line arises under the influence of higher continental aerosol concentrations and results in more precipitation after two hours of simulations.

A smaller indirect aerosol effect is also obtained when constraining the total indirect aerosol effect by taking the difference in the slope of the cloud droplet effective 
radius-aerosol index relationship between the POLDER satellite data (Bréon et al., 2002) and the ECHAM GCM results taken into account (Lohmann and Lesins, 2002). This reduces the total global mean aerosol effect from $-1.4 \mathrm{Wm}^{-2}$ to $-0.85 \mathrm{Wm}^{-2}$. Along the same lines, the cloud albedo effect is reduced from -0.7 to $-0.4 \mathrm{Wm}^{-2}$, when the empirical relationship between sulfate aerosol mass and the cloud droplet number concentration (Boucher and Lohmann, 1995) is constrained to match the relationship between the cloud droplet radius versus aerosol index from the POLDER and MODIS satellite data (Figure 3 and Quaas and Boucher, 2005).

At the Earth surface, however, both scattering and absorbing aerosols work in the same direction of reducing the amount of solar radiation reaching the surface. Since pre-industrial times, increasing emissions of aerosols from human activity and their precursors have caused a reduction of solar radiation at the surface ("solar dimming") by increasing aerosol and cloud optical depth. Such a reduction of $1.3 \%$ per decade over the land surfaces from 1961 to 1990 has been observed in many regions worldwide (e.g., Liepert, 2002; Stanhill and Cohen, 2001; Wild et al., 2004).

Likewise equilibrium simulations with a global climate model coupled to a mixed-layer ocean model with increasing aerosol particles and greenhouse gases due to human activity from pre-industrial times to present-day (Liepert et al., 2004) and transient simulations (Roeckner et al., 1999) showed that the decrease in solar radiation at the surface resulting from the increases in optical depth due to the direct and indirect anthropogenic aerosol effects is more important for controlling the surface energy budget than the greenhouse gas induced increase in surface temperature. The conductive flux from below the surface is negligible in the long-term mean surface energy budget. The other components of the surface energy budget (thermal
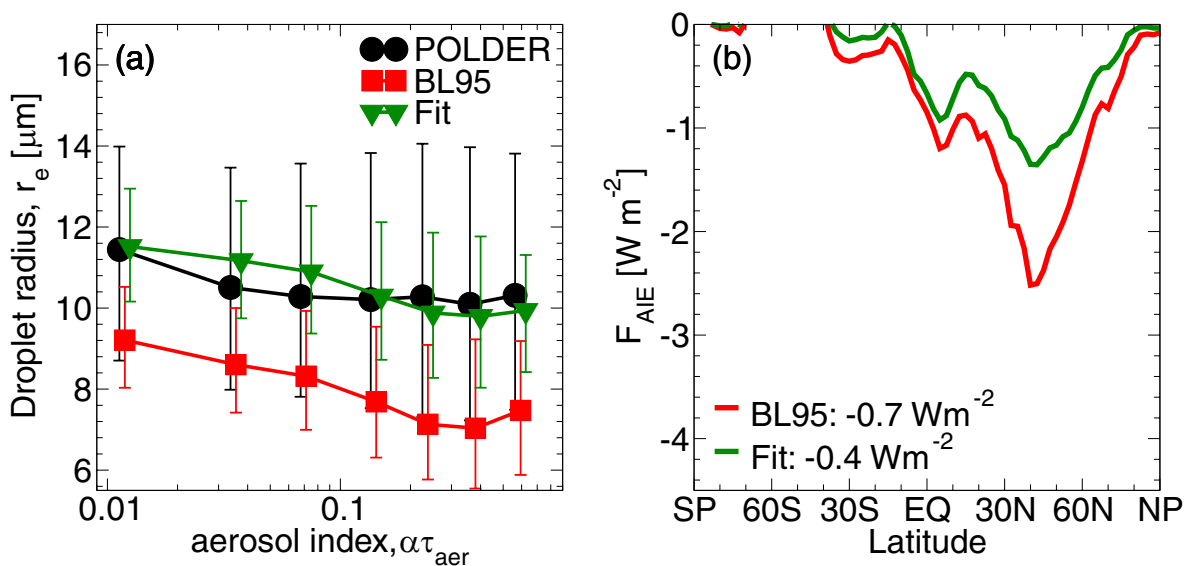

Figure 3. Fit of the cloud droplet radius vs aerosol index relationship (black: POLDER data, red: original (Boucher and Lohmann, 1995) parameterization, green: adaptation using parameters that match the POLDER data). For more details, please refer to Quaas and Boucher (2005). 


\begin{tabular}{|llll|}
\hline & Land & Ocean & Total \\
$\Delta$ Cloud cover $\%$ & +0.0 & +0.0 & +0.0 \\
$\Delta$ Cloud optical depth & +0.02 & +0.03 & +0.02 \\
$\Delta$ Liquid water path $\mathrm{g} / \mathrm{m}^{2}$ & +13 & +10 & +11 \\
$\Delta$ lce water path $\mathrm{g} / \mathrm{m}^{2}$ & +0.07 & -0.09 & -0.05 \\
\hline
\end{tabular}

\begin{tabular}{|l|}
\hline Aerosol \\
optical \\
depth \\
+0.07 \\
+0.02 \\
+0.03 \\
\hline
\end{tabular}

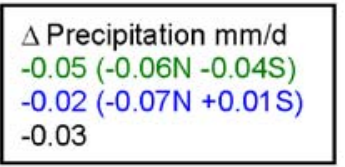

$\triangle$ Evaporation $\mathrm{mm} / \mathrm{d}$

$-0.03(-0.04 \mathrm{~N}-0.01 \mathrm{~S})$

$-0.03(-0.06 \mathrm{~N}-0.01 \mathrm{~S})$

$-0.03$

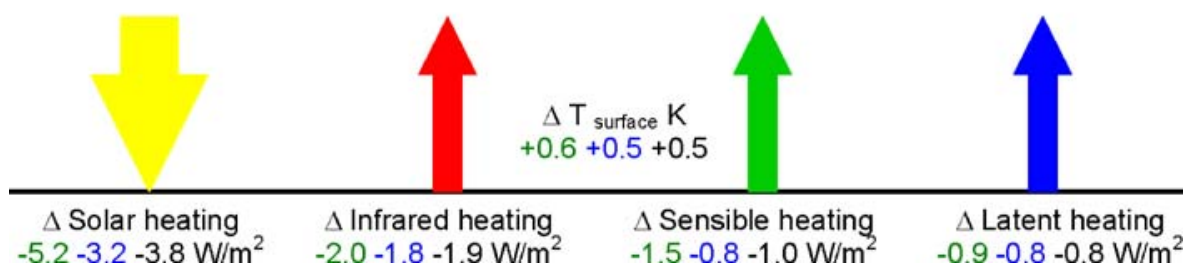

Figure 4. Simulated changes in atmospheric variables and surface energy and water fluxes. Changes are calculated as differences for a present day minus pre-industrial climate equilibrium experiments with a general circulation model where anthropogenic aerosol and greenhouse gas concentrations are modified. The arrows indicate direction and relative strengths of the energy fluxes. For more details, please refer to Liepert et al. (2004).

radiative flux, sensible and latent heat fluxes) decreased in response to the reduced input of solar radiation (Figure 4). This mechanism could explain the observations of decreased pan evaporation over the last 50 years (Roderick and Farquhar, 2002) and it agrees with the findings by Wild et al. (2004). As evaporation must equal precipitation on the global scale in these equilibrium climate simulations, a reduced latent heat flux led to a reduction in precipitation.

Recent surface observations, however, show that the long term decline in solar radiation at land surfaces turned into an increase in surface solar radiation during the 1980s (Wild et al., 2005; Pinker et al., 2005), in agreement with recent emission trends in the "old" industrial regions in the northern hemisphere (Krüger and Graß1, 2002) as well as with long-term black carbon trends in the Canadian Arctic (Sharma et al., 2004) and sulfate deposition declines over Europe and North America since 1978 (E. Holland, private communication). Thus, the increasing greenhouse effect may no longer be masked by an aerosol-induced decline in solar radiation, resulting in the enhanced warming observed since the 1990s (Wild et al., 2005).

Climate model simulations suggest that the decrease in global mean precipitation from pre-industrial times to the present day may reverse into an increase in global mean precipitation of about $1 \%$ in 2021-2050 as compared with 1961-1990. This 
is caused by the increased warming due to black carbon and greenhouse gases that will dominate over the sulphate cooling in the mid 21st century (Roeckner $\mathrm{et} \mathrm{al}$, 2006). In South Asia, absorbing aerosols in atmospheric brown clouds may have played a major role in the observed South Asian climate and hydrological cycle changes and may have masked as much as $50 \%$ of the surface warming due to the global increase in greenhouse gases (Ramanathan et al., 2005). Their simulations raise the possibility that, if current trends in emissions continue, the South Asian subcontinent may experience a doubling of the drought frequency in future decades.

\section{Conclusions}

The following conclusions regarding the various aerosol effects on clouds and climate can be reached:

- The range of model estimates for the cloud albedo indirect radiative forcing varies from -0.5 to $-1.9 \mathrm{Wm}^{-2}$. All models indicate a negative forcing, which on average is $-1 \mathrm{Wm}^{-2}$, with a standard deviation of $0.4 \mathrm{Wm}^{-2}$ (Lohmann and Feichter, 2005).

- The cloud lifetime effect varies considerably between the different models (from -0.3 to $-1.4 \mathrm{Wm}^{-2}$ ), resulting in an average forcing of $-0.7 \mathrm{Wm}^{-2}$ and a standard deviation of $0.5 \mathrm{Wm}^{-2}$ (Lohmann and Feichter, 2005).

- Estimates of the semi-direct effect range from +0.1 to $-0.5 \mathrm{Wm}^{-2}$. The variations arise from different locations of black carbon with respect to the cloud.

- Aerosol effects on stratiform or convective mixed-phase clouds are too uncertain until now to even provide an estimate.

In summary, it is not possible to obtain a best estimate of the total indirect aerosol effect from pre-industrial times to present-day solely from observations. The satellite record is not long enough and other existing long-term records do not provide the aerosol and cloud microphysical properties needed for such an assessment. Climate models by themselves have weaknesses that could bias the indirect effect. Thus, to obtain a best estimate of the indirect aerosol effect, measurements and models should be combined. Combining satellite measurements with climate model estimates offline, Lohmann and Lesins (2002) obtained a total indirect effect of $-0.85 \mathrm{Wm}^{-2}$, which falls within the range of the indirect effect as estimated from inverse simulations (Anderson et al., 2003). By applying the cloud droplet number versus fine mode aerosol optical depth relationship from MODIS directly within climate models, the total indirect effect is reduced even further to -0.3 to $-0.5 \mathrm{Wm}^{-2}$ (Quaas et al., 2006).

\section{Acknowledgements}

Ulrike Lohmann thanks Johannes Quaas for providing Figure 3. 


\section{References}

Anderson, T. L., Charlson, R. J., Schwartz, S. E., Knutti, R., Boucher, O., Rodhe, H., and Heintzenberg, J.: 2003, 'Climate forcing by aerosols - a hazy picture', Science 300, 1103-1104.

Boucher, O. and Lohmann, U.: 1995, 'The sulfate-CCN-cloud albedo effect: A sensitivity study with two general circulation models', Tellus Ser. B, 47, 281-300.

Bréon, F.-M., Tanré, D., and Generoso, S.: 2002, 'Aerosol effect on cloud droplet size monitored from satellite', Science 295, 834-838.

Ghan, S. J., Easter, R. C., Chapman, E., Abdul-Razzak, H., Zhang, Y., Leung, R., Laulainen, N., Saylor, R., and Zaveri, R.: 2001, 'A physically-based estimate of radiative forcing by anthropogenic sulfate aerosols', J. Geophys. Res. 106, 5279-5293.

Jones, A., Roberts, D. L., and Woodage, M. J.: 2001, 'Indirect sulphate aerosol forcing in a climate model with an interactive sulphur cycle', J. Geophys. Res. 106, 20,293-30,310.

Khain, A., Rosenfeld, D., and Pokrovsky, A.: 2005, 'Aerosol impact on the dynamics and microphysics of convective clouds', Q. J. R. Meteorol. Soc. 131, 2639-2663.

Kinne, S., Schulz, M., Textor, C., Guibert, S., et al.: 2006, 'An AeroCom initial assessment - optical properties in aerosol component modules of global models', Atmos. Chem. Phys. 6, 1815-1834.

Koren, I., Kaufman, Y. J., Remer, L. A., and Martins, J. V.: 2004, 'Measurements of the effect of smoke aerosol on inhibition of cloud formation', Science 303, 1342-1345.

Kristjánsson, J. E.: 2002, 'Studies of the aerosol indirect effect from sulfate and black carbon aerosols', J. Geophys. Res. 107, doi: 10.1029/2001JD000887.

Krüger, O. and Graß1, H.: 2002, 'The indirect aerosol effect over Europe', Geophys. Res. Lett. 29, doi: 10.1029/2001GL014081.

Liepert, B. G.: 2002, 'Observed reductions of surface solar radiation at sites in the United States and worldwide from 1961 to 1990', Geophys. Res. Lett. 29, doi: 10.1029/2002GL014910.

Liepert, B. G., Feichter, J., Lohmann, U., and Roeckner, E.: 2004, 'Can aerosols spin down the water cycle in a warmer and moister world?', Geophys. Res. Lett. 31, doi:10.1029/2003GL019060.

Lohmann, U.: 2002, 'A glaciation indirect aerosol effect caused by soot aerosols', Geophys. Res. Lett. 29, doi: $10.1029 / 2001$ GL014357.

Lohmann, U. and Lesins, G.: 2002, 'Stronger constraints on the anthropogenic indirect aerosol effect', Science 298, 1012-1016.

Lohmann, U. and Diehl, K.: 2006, 'Sensitivity studies of the importance of dust ice nuclei for the indirect aerosol effect on stratiform mixed-phase clouds', J. Atmos. Sci. 63, 968-982.

Lohmann, U. and Feichter, J.: 2005, 'Global indirect aerosol effects: A review', Atmos. Chem. Phys. 5, 715-737.

Lohmann, U. Feichter, J., Penner, J. E., and Leaitch, W. R.: 2000, 'Indirect effect of sulfate and carbonaceous aerosols: A mechanistic treatment', J. Geophys. Res. 105, 12,193-12,206.

Menon, S., DelGenio, A. D., Koch, D., and Tselioudis, G.: 2002, 'GCM simulations of the aerosol indirect effect: Sensitivity to cloud parameterization and aerosol burden', J. Atmos. Sci. 59, 692-713.

Pinker, R. T., Zhang, B., and Dutton, E. G.: 2005, 'Do satellites detect trends in surface solar radiation?', Science 308, 850-854.

Quaas, J. and Boucher, O.: 2005, 'Constraining the first aerosol indirect radiative forcing in the LMDZ GCM using POLDER and MODIS satellite data', Geophys. Res. Lett. 32, doi: 10.1029/2005GL023850.

Quaas, J., Boucher, O., and Bréon, F.-M.: 2004, 'Aerosol indirect effects in POLDER satellite data and the Laboratoire de Météorologie Dynamique-Zoom (LMDZ) general circulation model', J. Geophys. Res. 109, doi: 10.1029/2003JD004317.

Quaas, J., Boucher, O., and Lohmann, U.: 2006, 'A new estimate of the aerosol indirect radiative forcing by constraints of global climate models using satellite datasets', Atmos. Chem. Phys. 6, 947-955. 
Ramanathan, V., Chung, C., Kim, D., Bettge, T., Buja, L., Kiehl, J. T., Washington, W. M., Fu, Q., Sikka, D. R., and Wild, M.: 2005, 'Atmospheric brown clouds: Impacts on South Asian climate and hydrological cycle', Proc. Nat. Acad. Sc. 102, 5326-5333.

Roderick, M. L. and Farquhar, G. D.: 2002, 'The cause of decreased pan evaporation over the past 50 years', Science 298, 1410-1411.

Roeckner, E., Bengtsson, L., Feichter, J., Lelieveld, J., and Rodhe, H.: 1999, 'Transient climate change simulations with a coupled atmosphere-ocean GCM including the tropospheric sulfur cycle', J. Climate 12, 3004-3032.

Roeckner, E., Stier, P., Feichter, J., Kloster, S., and Esch, M.: 2006, 'Impact of carbonaceous aerosol emissions on regional climate change', Clim. Dyn., in press.

Rosenfeld, D. and Woodley, W. L.: 2000, 'Deep convective clouds with sustained supercooled liquid water down to $-37.5^{\circ} \mathrm{C}$ ', Nature $\mathbf{4 0 5}, 440-442$.

Rotstayn, L. D. and Penner, J. E.: 2001, 'Indirect aerosol forcing, quasi-forcing, and climate response', J. Climate 14, 2960-2975.

Sharma, S., Lavoué, D., Cachier, H., Barrie, L. A., and Gong, S. L.: 2004, 'Long-term trends of the black carbon concentrations in the Canadian Arctic', J. Geophys. Res. 109, doi: 10.1029/2003JD004331.

Stanhill, G. and Cohen, S.: 2001, 'Global dimming a review of the evidence for a widespread and significant reduction in global radiation with discussion of its probable causes and possible agricultural consequences', Agric. For. Meteorol. 107, 255-278.

Takemura, T., Nozawa, T., Emori, S., Nakajima, T. Y., and Nakajima, T.: 2005, 'Simulation of climate response to aerosol direct and indirect effects with aerosol transport-radiation model', J. Geophys. Res. 110, doi:10.1029/2004JD00502.

Wild, M., Ohmura, A., Gilgen, H., and Rosenfeld, D.: 2004, 'On the consistency of trends in radiation and temperature records and implications for the global hydrological cycle', Geophys. Res. Lett. 31, doi: 10.1029/2003GL019188.

Wild, M., Gilgen, H., Roesch, A., Ohmura, A., Long, C. N., Dutton, E. G., Forgan, B., Kallis, A., Russak, V., and Tsvetkov, A.: 2005, 'From dimming to brightening: Decadal changes in solar radiation at Earth's surface', Science 308, 847-850.

Williams, K. D., Jones, A., Roberts, D. L., Senior, C. A., and Woodage, M. J.: 2001, 'The response of the climate system to the indirect effects of anthropogenic sulfate aerosols', Clim. Dyn. 17, $845-856$. 